\title{
"Media for Capability" of Children with Disabilities: Development of the Japanese Augmentative Alternative Communication App by Tablet for Persons with Hard of Hearing
}

\author{
Kuniomi Shibata \\ Graduate School of \\ International Studies \\ Tsuda College \\ Kodaira, Tokyo \\ kshibata@tsuda.ac.jp
}

\author{
Akira Hattori \\ Department of Grobal Media \\ Komazawa University \\ Setgaya, Tokyo \\ hattori@komazawa-u.ac.jp
}

\author{
Sayaka Matsumoto \\ Department of Social \\ Information Studies \\ Otsuma Women's University \\ Chiyoda, Tokyo \\ matsumotosayaka@gmail.com
}

\begin{abstract}
Over the past few decades, a considerable number of studies have been conducted on the communication for persons with Hard of hearing and Deaf in Japan. But little attention has been given to the take advantage of Information Technology devices to support the communication for Hard of hearing children.

By the way, the present study analyses in greater detail the survey results summarized in the importance of the "Tablet-Media". We discuss our communication assist software to express texts and images by Android application for children with Hard of hearing. In this paper, this app is analyzed using the "Capability theory" with emphasis on the power of self-expression and the right to self-determination of persons with disabilities.

The results of our performance tests showed that our system was very helpful in order to provide their "Capability" for Hard of hearing children. We suggest the potential to combine our App is what we should call "Media for Capability" of communication in children with Hard of hearing.
\end{abstract}

\section{Introduction}

\subsection{Background: Increase in Population with Hard of hearing and Deaf}

There has been a renewal of interest in the communication for persons with Hard of hearing and Deaf in Japan. We will begin by considering the context and trend of the social support for Japanese Hard of hearing people.
Today one in five people in Japan is elderly, a proportion set to rise even further in the future, it is forecast that by 2060 one in 2.5 Japanese $(39.9 \%$ of the population) will be 65 or older, an unprecedented level in any society [1]. That trend will naturally lead to an increase in elderly people suffering from age-related hearing loss, in which hearing gradually deteriorates with age.

In addition to this information, the number of persons with physical disabilities is $31 \%$ (Figure 1), which of persons with intellectual disabilities are $6 \%$, and that of persons with mental disabilities is $25 \%[2]$.

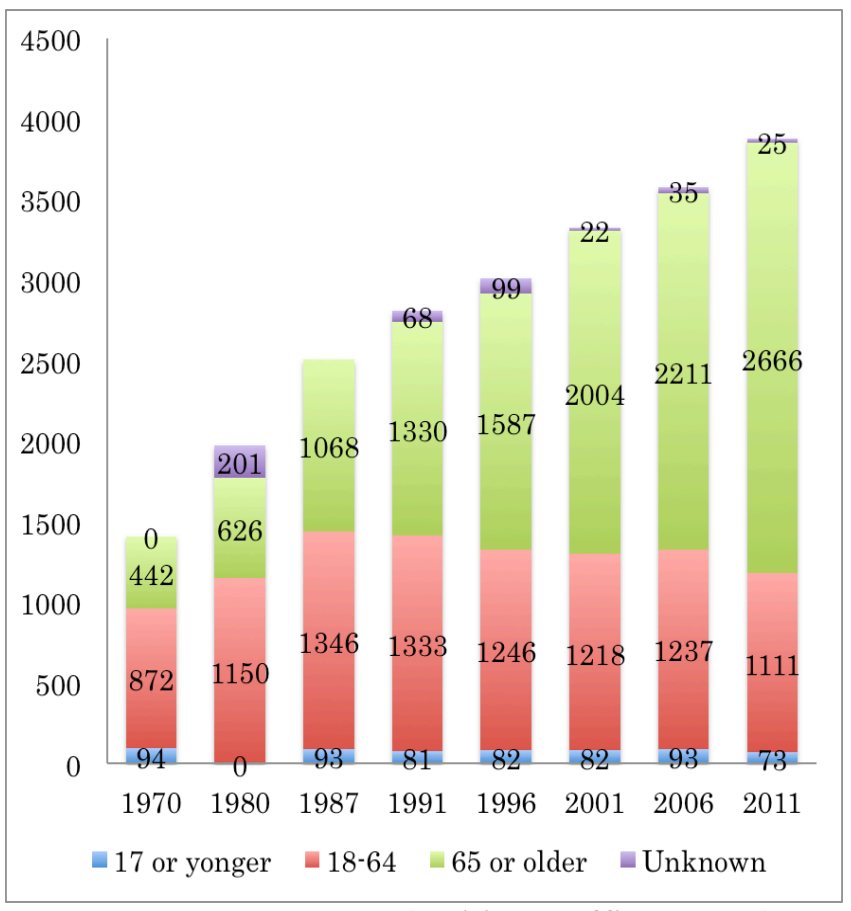

(Cabinet Office, 2014) 
Figure 1 : Trends in the Number of Persons with Disabilities by Age (Children and Persons with Physical Disabilities)

The number of Japanese suffering from hearing loss, which already stands at 20 million when latent cases are included, is thus expected to increase even further.

Reflection on some of these will make clear that we should take the challenge to desterilize that people with disabilities becomes a resource of society rather than a burden of society.

The rapid graying of Japanese society deserves attention, it is the background of our research. But, to inquire further into the matter would lead us into that specialized area of aging, and such a digression would undoubtedly obscure the outline of our agreement. The focus which we have to consider is the wide trend of the situation many persons with disabilities become using Media and Information Communication Technology to solve their problems.

Nevertheless, we could show promising advances about Information and Assistive Technology. ICT and Assistive Technology are spreading across some boundaries.

For example, comparing Internet usage rates by age group between 2002 and 2014 shows that usage rates have ascended in all age groups (Figure 2), but that the percentage increases has been particularly pronounced among seniors 60 and older [3] Moreover, the majority of it is the persons with disabilities.

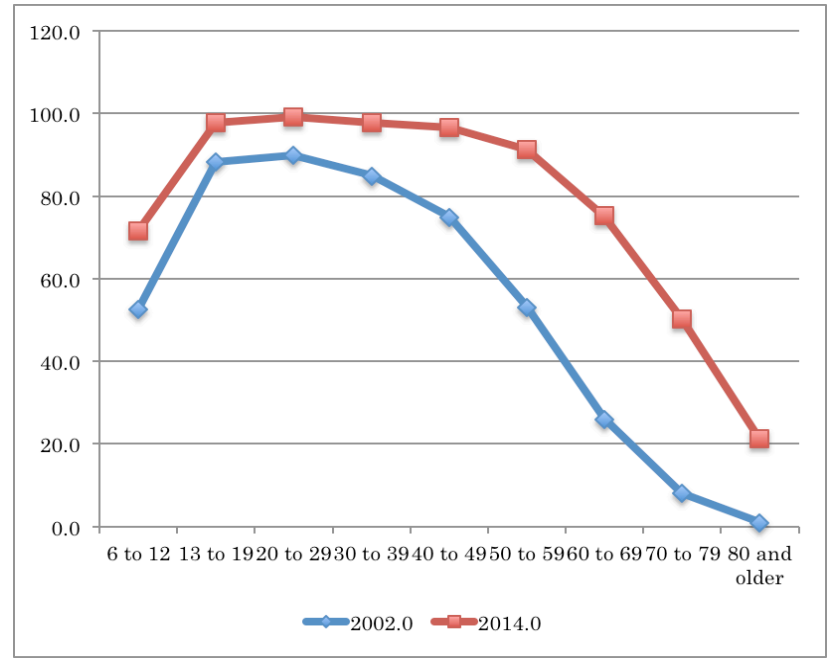

(MAIC 2015)

Figure 2: Increase in Internet usage rates by age group (including persons with disabilities)
The expansion of ICT use is phenomenon common to all age groups including persons with disabilities detailed examinations reveal certain tendencies.

\subsection{Current Situation and Previous studies: Augmentative Alternative Communication for Persons and Children with Hard of hearing}

In addition and simultaneously, very few attempts have been made at supporting the communication for Hard of hearing children. Newborn hearing screening tests have been implemented in Japan. Approximately 27,000 neonates $(2.5 \%$ of newborn) are screened annually through public-funded programs [4]. A rapid rise in population of Hard of hearing babies results from Newborn hearing screening tests.

It is necessary to commitment to the trend in increasing Hard of hearing population. Several studies have been made on "Augmentative Alternative Communication" (AAC). AAC is an assistive technology for persons with communicative disabilities, remarkably children.

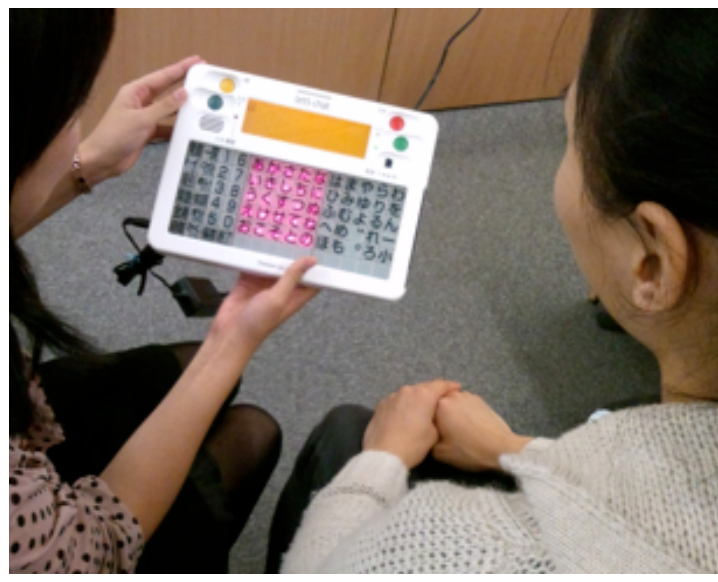

Figure 3. Example of using Augmentative Alternative Communication device

ICT, Tablet has hitherto been regarded as an only aid for persons of ordinary ability. The present study analyses in greater detail the survey results summarized in the importance of the Tablet for AAC [5]. Gosnell etc. suggested that Augmentative and Alternative Communication is needed for persons with disabilities [6]. AAC is an assistive technology for persons with communicative disabilities, remarkably children.

As McNaughton and Light actually pointed out, the potential benefits and significant challenges of mobile devices enhance communication capabilities for 
persons with disabilities [5]. Also, Alliano et al. described Tablet applications as supporting augment and alternative communication abilities of persons with disabilities [7]. They are useful, convenient and flexible because of their portability, affordability, and social acceptance [7].

Although studies have been made on AAC for Autism Spectrum Disorders [8], little attention has been given to the take advantage of AAC by Information Communication Technology devices to promote language speaking and knowledge acquisition for Hard of hearing children in Japan.

The importance of Tablet-Media for children with Hearing-Heard cannot be overemphasized. It has been recognized that some Augmentative Alternative Communication devices are helpful for children with Hard of hearing not only acquiring language but developing the capability of communication. We suggest the potential to combine our communication assist software to express texts and images by Android app is what we should call "Media for Capability" of cultivating the power of self-expression, and giving the right to self-determination, and communication in children with Hard of hearing.

\section{Theoretical Approach}

The most importance of AAC by ICT is that it will come to fruition of the self-expression and selfdetermination for people with disabilities. Remarkably, many children with Hard of Hearing are facing plenty of hurdles to improve their capability to express their thought absolutely clear, and their decision perfectly right. Although studies as we have seen have been made on the superficial, temporal, and extrinsic assists of communications, very few attempts have been made at developing their capabilities themselves. This is our motivation why we are developing a new media app from the standpoint of the capability approach.

It is inevitable that we will focus on the capability approach for the moment to discuss the condition for the exercise of children with disabilities. The capability approach to a person's advantage is concerned with evaluating it in terms of his or her actual ability to achieve various valuable functioning as a part of living [9]. The approach is based on a view of living as a combination of various 'doings and beings', with quality of life to be assessed in terms of the capability to achieve valuable functioning [9]. Amartya Sen gives a good account of "Capability" that has a connection with the human development approach.

Others may be more complex, but still widely valued, such as achieving self-respect or being socially integrated. Individuals my, however, differ a good deal from each other in the weights they attach to these different functionings - valuable though they may all be - and the assessment of individual and social advantages must be alive to these variations [9].

The capability approach focuses "can the person actually do these things nor not?" One may say, as Sen in fact does, that the capability is closely connected with the power of self-expression and the right to selfdetermination of persons with disabilities. In order to ensure the success of children's with disabilities participation to society, it is necessary to develop their capabilities. We shall now concentrate on the domestic matters, the capability approach with emphasis on how to cultivate the power of self-expression, and give the right to self-determination for people and children with disabilities in the Japanese Society.

\section{Development of Tablet Media and Android application for children with Hard of Hearing}

\subsection{Concept of our application}

This approach leads us to develop the media that support their expression and determination for children with hard of hearing. A device for their communications is characterized as follows:

(1) Being able to use in daily living

We design such a device as an application running on an Android tablet. Using a tablet computer leads to application images like AAC devices. However, ACC devices assist speech and our application assists listening. They are close but not the same.

(2) Showing photographs and pictograms depending on the situation

Our application uses Android's speech recognition system to extract communications from daily living in real time.

(3) Showing images to share the situation

In our application, speakers can show not videos but images to explain the situations/real conversation scenes.

These points is necessary for cultivating the power of self-expression, and giving the right to selfdetermination,

As to (3), our application store real conversation scenes as images and show them according to the scenes. The images contain photographs and 
pictograms to provide a simple explanation about the situation. We select such pictograms that commonly appear in an instructional situation for Hearing-Hard children. This is because we are going to evaluate a prototype of the application in such situation.

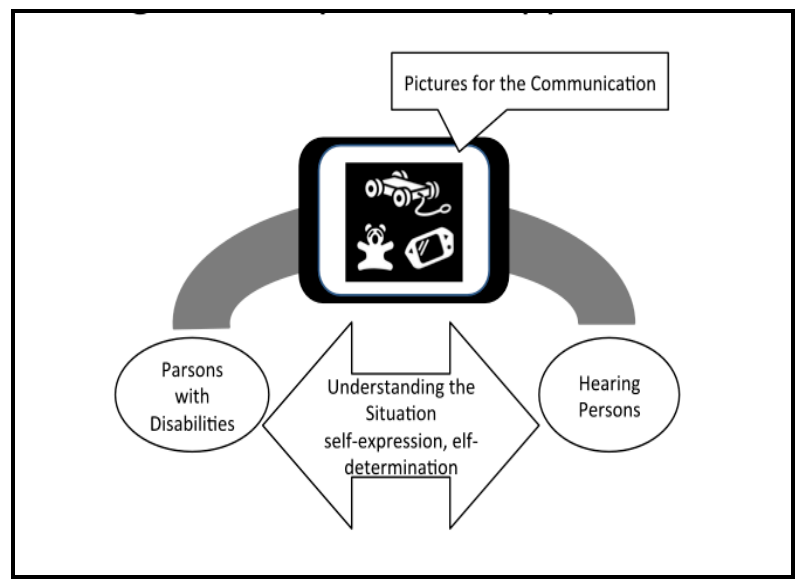

Figure 4. Concept of our application

\subsection{Outline and System Architecture}

Figure 2 shows the structure of our Android application. The application has three functions. The first is to add photographs and pictograms. The second is to extract words used real conversation after another through speech recognition system and to store the conversation as a sequence consisting of the photographs and pictograms according to the words. The third is to edit the sequence later. Fig. 5 shows the basic structure of our application.

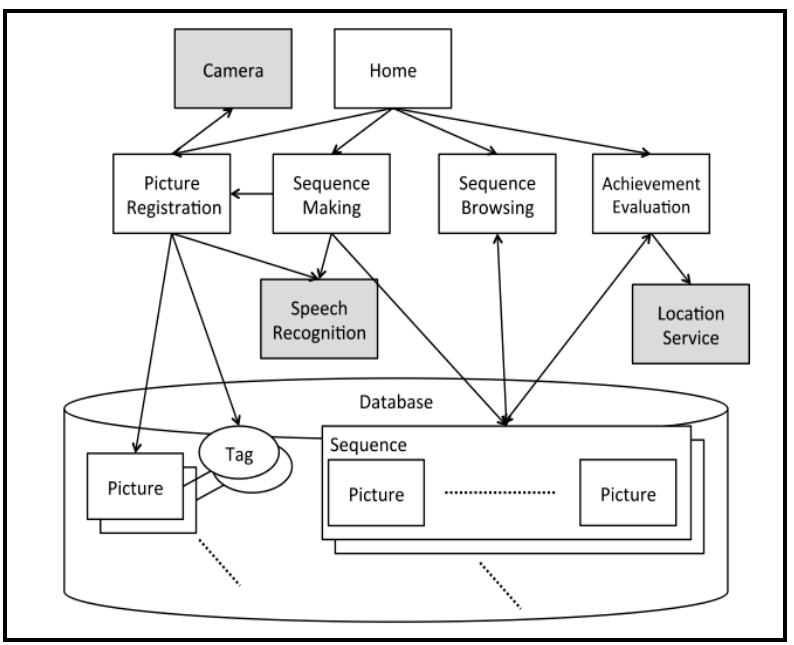

Figure 5. Structure of our Android application

\subsection{User Interface}

This application runs on a tablet device and uses its functionality. Our application mainly consists of four functions. They are picture registration, sequence making, sequence browsing, and achievement evaluation.

It has communication mode and schedule mode. The former is to support a communication and the latter is to support preparing for transitions between activities

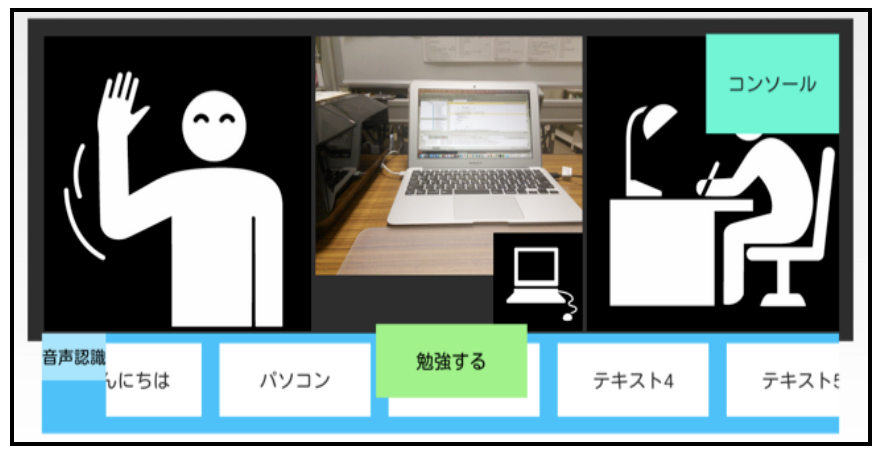

Figure. 6 User interface

\section{a) Communication Mode}

We can carry out speech recognition and search for a picture using the recognized word. The pictures are stored to a tablet device. We can make a sentence of the pictures and talk by using the sequence.

Our application recognizes speech of hearing persons using speech recognition system and show pictures corresponding to the recognized words in order. By the sequence of the pictures, the application supports children and persons with disabilities in communication and preparing for transitions between activities.

\section{b) Schedule Mode}

Using the schedule mode, on the other hand, we can make a schedule to by setting the place and time to a sequence in the same manner.

In our application, pictures include pictograms, YUBI MOJI (Japanese finger spell), clock images, photographs, and maps. Default pictures are pictograms, YUBI MOJI, and clock images. The pictograms contain important things and matter in everyday life, for example, man, what to eat, events, time, home, etc. 


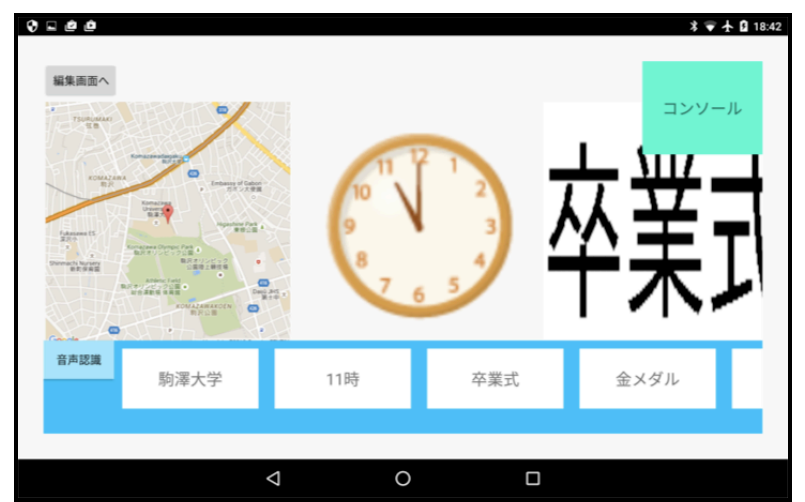

Fig. 7 an example of sequence

\section{Evaluations and analysis: User Experiences of the application}

\subsection{Preliminary Evaluation}

The following figure 8 shows a scene that two persons have a conversation using our prototype. They put a tablet computer in which our application has been installed on a table, and the left-hand side person is a speaker and trying to show photographs and pictograms explain the real conversation scenes to a child with Hard of Hearing.

We conducted two evaluation of our Tablet-Media by using the prototype. The first preliminary experimental period is on November 21, 2013. The test conducted a survey among 17 cllege students without disabilities. Fig. 8 shows the result.

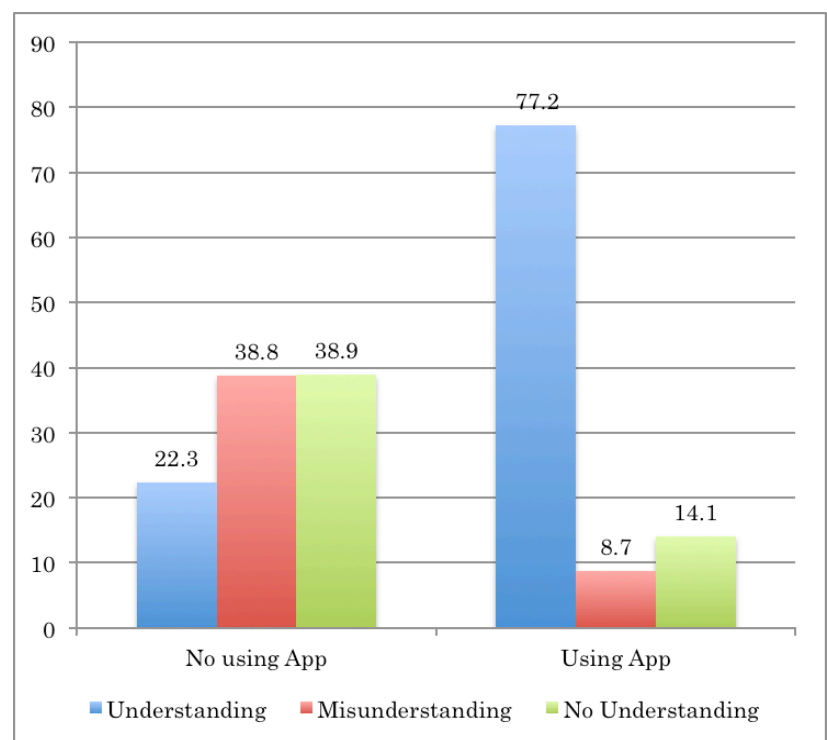

Figure 8. The result of Preliminary Evaluation1
The following results were obtained:

1) Understanding: $22.3 \%$ to $77.2 \%$ by using the app.

2) Misunderstandings: $38.8 \%$ to $8.1 \%$ by using the app.

3) No understanding: $38.9 \%$ to $14.1 \%$ by using the app.

It can be seen while many users of our application grade the understanding much. The results suggested there are some advantages not only persons without disabilities but children with Hard of Hearing.

\subsection{Case Studies (Evaluation 2)}

We will now develop the app for capability of children with disabilities a little further. The second experimental period is on July 22, 2015 to September 7. We call the preliminary evaluation 2 for persons with disabilities, "Case Studies".

Experimental participants (below is called A, B, C, $D, E)$ have difficulties to communicate with by hearing disabilities or developmental disorders. They use tablets installed our application for their activity. Since the number of people was a little, we don't show the result by the numerical data. Fuller information and discussion will be presented in the conference. The results are shown below.

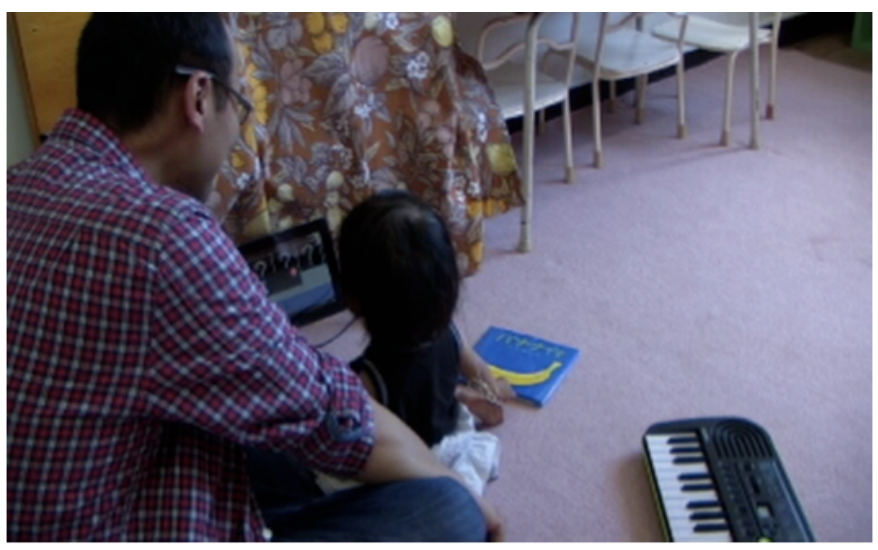

Figure 9. Communication using Prototype App (see the Video)

- "The application was effectual in daily conversation."

- $\quad$ "I will tell my schedule dumb down. “

- "Showing photographs and pictograms homologized the captions makes the real conversation easy-to-understand,"

- $\quad$ "We can record what someone says and recall it later." 
On the other hand, as for the view which points out an improving point, the following was obtained.

- "If I can use video of sign language, this application will be better."

- "An user is confused because there is a problem with the design."

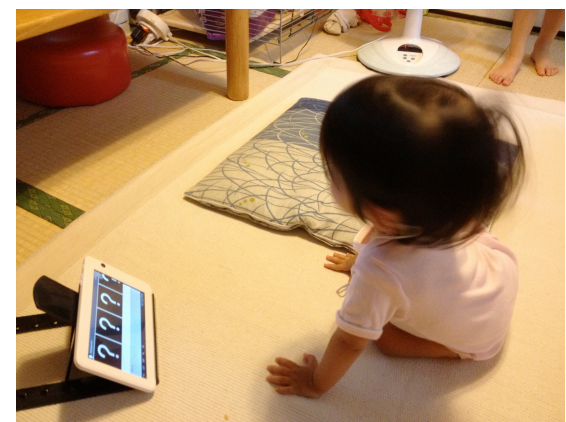

\section{Figure 10. Communication using Prototype App}

We got comments about pictograms and it became clear that the users could do scheduling and confirming enjoyably. It is found from the comments that this app can support these children's communication, their selfexpression, and their self-determination.

\section{Conclusion}

The result of our performance tests clearly showed that our system was very helpful in order to assist their self-expression, and their self-determination. The comments obtained from the experimental participants suggested that our proposed application could be effectively used when users talk about their daily lives and when they show today's activities. That is, our application could be useful for those who have difficulties in communication with spoken language and preparing for transitions between activities.

Therefore, it seems reasonable to conclude that our tablet app could provide "Capability" for children with hard of hearing. This Tablet-Media would go beyond assisting Hearing-Hard children to communicate with others. It would enhance the potential of the power of self-expression, and the right to self-determination, such that strengthen mutual understanding through multi-medial integration of texts, sounds, and images. We can put in perspective the novel application for tablet computers and changes of communications brought by it. To verify the potential, we need to develop an adaptive application that can be used in a variety of real conversation scenes. We will clarify the real image of the Tablet-Media to provide their capability, to assist the communication to cultivating the power of self-expression, and giving the right to self-determination.

\section{Acknowledgment}

We would like to express our gratitude to all participants of the preliminary experiments, especially persons with disabilities. This work was supported by the Grants of Telecommunications Advancement Foundation 2015, and KAKENHI, Grant-in-Aid C (15K03959), Fostering Joint International Research (15KK0132), from the Japan Society for the Promotion of Science.

\section{References}

[1] Japanese Cabinet Office. Annual Report on the Aging Society 2016. Insatsu Tsuhan K.K., Tokyo, 2016, p. 3

[2] Japanese Cabinet Office. Annual Report on the Aging Society 2014. Insatsu Tsuhan K.K., , 2014, Tokyo, pp.2-5.

[3] Ministry of Internal Affairs and Communications, Japan, 2015, White paper Information and Communications in Japan, Insatsu Tsuhan K.K., pp.2-4. [4] Okubo S, Takahashi M, Saito T, Kai I., Evaluation of universal newborn hearing screening in Japan: an analysis of the literature, Nihon Koshu Eisei Zasshi. 2005, Nov;52(11), pp.928-33.

[5] D. McNaughton, J. Lighta, The iPad and Mobile Technology Revolution: Benefits and Challenges for Individuals who require Augmentative and Alternative Communication Volume 29, Issue 2, 2013, pp. 107116.

[6] J. Gosnell, J. Costello and H. Shane, Using a Clinical Approach To Answer "What Communication Apps Should We Use?", Perspectives on Augmentative and Alternative Communication, Vol. 20, No. 3, 2011, pp. 87-96,.

[7] A. Alliano, K. Herriger, A. D. Koutsoftas and T. E. Bartolotta, A Review of 21 iPad Applications for Augmentative and Alternative Communication Purposes, Perspectives on Augmentative and Alternative Communication, Vol. 21, No. 2, ,2012, pp. 60-71.

[8] M. Flores, K. Musgrove, etc.,A Comparison of Communication Using the Apple iPad and a Picturebased System, Augmentative and Alternative Communication, Volume 28, Issue 2, 2012, pp. 74-84.

[9] A. Sen, , "Capability and Well-Being", Nussbaum, M. C., \& Sen, A., 1993 The Quality of Life, Oxford University Press, pp. 30-32. 